Trauma Surgery \& Acute Care Open

\title{
Vasopressin analog terlipressin attenuates kidney injury in hemorrhagic shock
}

\author{
Letícia Urbano Cardoso de Castro, ${ }^{1}$ Keila Kazue Ida ${ }_{1}{ }^{2}$ Denise Aya Otsuki, ${ }^{2}$ \\ Talita Rojas Sanches, ${ }^{1}$ Rildo A Volpini, ${ }^{1}$ Emilyn da Silva Borges, ${ }^{2}$ \\ Luiz-Marcelo Sá Malbouisson, ${ }^{2}$ Lúcia Andrade ${ }^{1}$
}

${ }^{1}$ Division of Nephrology, University of São Paulo School of Medicine, São Paulo, Brazil ${ }^{2}$ Anesthesiology Department, University of São Paulo School of Medicine, São Paulo, Brazil

\section{Correspondence to Professor Lúcia Andrade; luciacan@usp.br}

This paper was presented in part as a poster at the Critical Care Congress, Society of Critical Care Medicine, San Francisco, California, USA, 2014.

Received 11 August 2016 Accepted 30 August 2016

To cite: Cardoso de Castro LU, Ida KK, Otsuki DA, et al. Trauma Surg Acute Care Open Published Online First: [please include Day Month Year] doi:10.1136/tsaco2016-000039

\section{ABSTRACT}

Background In hemorrhagic shock (HS), volume replacement with crystalloid solution can restore the hemodynamic status and decrease mortality. However, it can also lead to tissue edema and pulmonary congestion, as well as increasing vascular permeability. Here, we analyzed the effects that resuscitation with lactated Ringer's solution (LRS) or administration of the vasopressin analog terlipressin has on renal function in a porcine model of HS.

Methods Using pressure-controlled bleeding, we induced pigs to $\mathrm{HS}$, maintaining mean arterial pressure (MAP) at $40 \mathrm{~mm} \mathrm{Hg}$ for $30 \mathrm{~min}$. Animals were divided into 4 groups: sham (anesthesia only); shock-only (HS induction); shock+LRS (HS induction and subsequent resuscitation with LRS at 3 times the volume of blood removed); and shock+Terli (HS induction and subsequent bolus administration of $2 \mathrm{mg}$ of terlipressin). Parameters were evaluated at baseline, then at 30,60, and $120 \mathrm{~min}$ after treatment (T30, T60, and T120, respectively). Animals were euthanized at T60 or T120.

Results Both treatments restored MAP to baseline values. At T30 and T60, creatinine clearance was highest in shock+LRS pigs, whereas it was highest in shock +Terli pigs at T120. Both treatments initially induced hyponatremia, although urinary excretion of all ions was higher in shock+LRS pigs at T30. Both treatments restored $\mathrm{Na}-\mathrm{K}-2 \mathrm{Cl}$ cotransporter expression, whereas only terlipressin restored aquaporin 2 expression. Both treatments also prevented HS-induced acute tubular necrosis. Expression of the vasopressin receptors V1a and V2 was highest in shock-only pigs. At T120, V1a expression was lowest in shock+LRS pigs.

Discussion Terlipressin might be useful for preventing HS-induced acute kidney injury.

\section{INTRODUCTION}

Hemorrhagic shock (HS), a condition resulting from rapid, significant loss of intravascular volume, can lead to hemodynamic instability, followed by decreased oxygen delivery, inadequate tissue perfusion, cell hypoxia, increased vascular permeability, and organ damage. ${ }^{1}$ In cases of trauma, HS is the leading cause of morbidity and mortality. ${ }^{2}$ Every year, trauma kills 5.8 million people, making it the third leading cause of death and disability, after cardiovascular disease and cancer. ${ }^{2}$ In the city of São Paulo, Brazil, the incidence of death resulting from traffic accidents is 9.6/100 000 population, compared with 3.3/100 000 population in New York City. ${ }^{3-5}$ The first organs to become ischemic after hemorrhage or trauma are the kidneys and the brain. ${ }^{6}$ Acute kidney injury (AKI), which is associated with high mortality, involves a rapid decrease in the glomerular filtration rate, often caused by vasoconstriction or a loss of autoregulation. ${ }^{7}$ In addition, ischemia and reperfusion activate mechanisms of cell death, ${ }^{8}$ including apoptosis, autophagy-associated cell death (cytoplasmic vacuolization, loss of organelles, and accumulation of vacuoles with membrane whorls), and necrosis (progressive swelling of cells and organelles; plasma membrane rupture; and leakage of proteases and lysosomes into the extracellular compartment). Furthermore, ischemia/reperfusion injury is associated with a decrease in renal expression of the $\mathrm{Na}-\mathrm{K}-2 \mathrm{Cl}$ cotransporter (NKCC2) - the major transporter for apical sodium reabsorption by the thick ascending limb-and of aquaporin 2 (AQP2) - the vasopressin-regulated water channel-which could contribute to increasing urinary excretion of sodium, chloride, and water. ${ }^{9}{ }^{10}$ The vasopressin receptors V1a and V2 also play a role in HS. The V1a receptor, which is found in the vascular smooth muscle, is responsible for the vasoconstriction induced by administration of vasopressin, whereas the V2 receptor, which is predominantly found in the distal tubule and collecting ducts of the kidney, mobilizes AQP2 to the apical membrane. ${ }^{11-13}$

The standard resuscitation protocol for HS mandates the use of large volumes of crystalloids. However, that practice can have adverse effects, such as interstitial edema in the gut, lungs, and kidneys; ${ }^{14-17}$ increased production of pro-inflammatory cytokines; ${ }^{18}$ and increased intracranial pressure. ${ }^{19}$ The vasopressin analog terlipressin has been shown to be effective as a vasoconstrictor agent in the management of catecholamine-resistant arterial hypotension in septic shock and of acute gastrointestinal bleeding in patients with hepatorenal syndrome. ${ }^{20}{ }^{21}$ In a recent study employing a porcine model of HS, we showed that early treatment with terlipressin was effective in restoring cerebral perfusion pressure, as well as in preventing HS-induced changes in the brain expression of markers of water balance, oxidative stress, and apoptosis. ${ }^{22}$ However, in that same study, animals receiving lactated Ringer's solution (LRS) showed a greater increase in intracranial pressure than did those receiving terlipressin, a difference that could be attributed to an increase in brain water content in the former group. Nevertheless, we found that terlipressin maintained cerebral perfusion pressure while keeping intracranial pressure at levels similar to those observed for a control group. ${ }^{22}$ In the present study, which was conducted in parallel with 
that study, we used the same porcine model in order to test our hypothesis that the effectiveness of terlipressin in treating HS-induced AKI is equivalent and possibly superior to that of resuscitation with LRS.

\section{MATERIALS AND METHODS}

Ethical aspects

All experimental procedures were approved by the Medical Ethics Committee of the University of São Paulo University Hospital (Protocol no. 067/11) and by the Medical and Research Ethics Committee of the University of São Paulo School of Medicine Hospital das Clínicas (Protocol no. 280/13). The animals (Large White pigs, all female) were obtained from a local farm that specializes in providing animals for use in research and certifies that the animals it provides are free of disease. This study was conducted in parallel with another study employing the same animals and procedures. ${ }^{22}$ However, that study evaluated the effects that HS and the two different treatments had on cerebral perfusion pressure and brain tissue markers of water balance, oxidative stress, and apoptosis.

\section{Preparatory procedures}

Female large White pigs $(\mathrm{n}=47)$, weighing $20-30 \mathrm{~kg}$, were fasted (with free access to water) for 12 hours before the experiments. The animals were premedicated with intramuscular injections of ketamine $(5 \mathrm{mg} / \mathrm{kg})$ and midazolam $(0.25 \mathrm{mg} / \mathrm{kg})$, after which anesthesia was induced with intravenous propofol ( $7 \mathrm{mg} / \mathrm{kg})$. After endotracheal intubation, anesthesia was maintained with isoflurane vaporized into a mixture of $40 \%$ oxygen and $60 \%$ nitrogen. Each animal was then connected to a ventilator (Fabius GS Premium; Dräger, Lübeck, Germany) on which the tidal volume was set at $8 \mathrm{~mL} / \mathrm{kg}$, with a positive end-expiratory pressure of $5 \mathrm{~cm} \mathrm{H}_{2} \mathrm{O}$. The respiratory rate was adjusted to maintain normocapnia (arterial carbon dioxide tension, $35-45 \mathrm{~mm} \mathrm{Hg}$ ). Throughout the experiments, the animals received continuous infusion of LRS $(4 \mathrm{~mL} / \mathrm{kg} /$ hours of ventilation) and pancuronium $(0.3 \mathrm{mg} / \mathrm{kg} / \mathrm{hours}$ of ventilation). Body temperature was maintained at $38^{\circ} \mathrm{C}$ using a heated mat (Medi-Therm II; Gaymar Industries, Orchard Park, New York, USA). The two femoral arteries were catheterized for measurement of mean arterial pressure (MAP) and withdrawal of blood to induce HS, respectively. Another catheter was inserted into the right femoral vein for later administration of treatments. At each time point evaluated, arterial and mixed venous blood were sampled for analysis-which included measurement of serum levels of hemoglobin, sodium, and potassium-in a blood gas analyzer (ABL 555; Radiometer, Copenhagen, Denmark).

\section{Ancillary preparatory procedures}

For the purposes of the parallel study, ${ }^{22}$ the same animals ${ }^{i}$ employed in our study were submitted to a number of procedures unrelated to the evaluation of renal function. A pulmonary artery catheter was surgically introduced into the right internal jugular vein and advanced to the wedge position. Two burr holes were placed over the right and left coronal sutures, respectively. In the right hemisphere, an intraparenchymal probe was inserted into the cerebral cortex for measurement of brain tissue oxygen pressure. In the left hemisphere, a fiberoptic probe was inserted into the epidural space for continuous monitoring of intracranial pressure.

${ }^{i}$ Although the parallel study employed the same animals, in the same groups, the designations used in order to identify the experimental groups differed from those used in the present study: HAEMO versus shock-only; LR versus shock+LRS; and TERLI versus shock+Terli.

\section{Experimental design}

Following surgical preparation, animals were allowed to stabilize for $30 \mathrm{~min}$ before being randomly divided into four groups: sham $(n=6)$, consisting of animals that were anesthetized but were not subjected to HS; shock-only $(n=12)$, consisting of animals subjected to HS and left untreated; shock+LRS $(n=15)$, consisting of animals subjected to HS and subsequently treated with LRS (at a volume equal to three times that of the blood removed); and shock+Terli $(n=14)$, consisting of animals subjected to HS and subsequently treated with a $2 \mathrm{mg}$ bolus of terlipressin (Glypressin; Ferring Pharmaceuticals, Copenhagen, Denmark). Randomization was performed, prior to baseline measurements, as previously described. ${ }^{9}$

Using pressure-controlled bleeding, we induced pigs to HS, maintaining the target MAP $(40 \mathrm{~mm} \mathrm{Hg})$ for $30 \mathrm{~min}$. For all animals, data were collected at four time points: baseline (prior to blood removal); shock30 (30 min after achieving the target MAP, immediately prior to treatment); T30 (30 min after treatment); and T60 (60 min after treatment). For some of the animals in each group (sham, $\mathrm{n}=2$; shock-only, $\mathrm{n}=3$; shock +LRS, $\mathrm{n}=9$; and shock+Terli, $\mathrm{n}=8$ ), the study was continued for an additional $60 \mathrm{~min}$, allowing data to be collected at a fifth time point (T120, $120 \mathrm{~min}$ after treatment). At the end of the study period (T60 or T120), animals were euthanized with an overdose of isoflurane. Kidney fragments were frozen in liquid nitrogen and stored at $-70^{\circ} \mathrm{C}$ or fixed in $10 \%$ neutral-buffered formalin solution for 24 hours and in $70 \%$ alcohol thereafter.

\section{Analysis of blood and urine}

Urine samples were centrifuged in aliquots to remove suspended material, and the supernatants were analyzed. Serum and urinary levels of phosphorus, chloride, and magnesium were measured with ion-selective electrodes (NOVA Biomedical, Waltham, Massachusetts, USA), whereas serum levels of creatinine and urea were measured with kinetic techniques. We measured urine osmolality using a freezing-point osmometer (3D3; Advanced Instruments, Norwood, Massachusetts, USA).

Creatinine clearance was calculated by the following formula:

$$
\mathrm{C}_{\text {creat }}=\left(\mathrm{U}_{\text {creat }} \times \mathrm{U}_{\text {volume }}\right) / \mathrm{P}_{\text {creat }}
$$

where $\mathrm{C}_{\text {creat }}$ is the creatinine clearance, $\mathrm{U}_{\text {creat }}$ the urinary concentration of creatinine $(\mathrm{mg} / \mathrm{dL}), \mathrm{U}_{\text {volume }}$ the urine output in microliters per $30 \mathrm{~min}$, and $\mathrm{P}_{\text {creat }}$ the plasma concentration of creatinine $(\mathrm{mg} / \mathrm{dL})$.

\section{Kidney fractions}

Kidney samples were homogenized in ice-cold isolation solution (200 mM mannitol, $80 \mathrm{mM}$ HEPES, and $41 \mathrm{mM}$ potassium hydroxide, $\mathrm{pH}$ 7.5) containing a protease inhibitor cocktail (Sigma Chemical, St Louis, Missouri, USA) in a homogenizer (PT 10/35; Brinkmann Instruments, Westbury, New York, USA). To remove nuclei and cell debris, homogenates were centrifuged at $2000 \times \mathrm{g}$ for $15 \mathrm{~min}$ at $4^{\circ} \mathrm{C}$. Supernatants were isolated, and protein was quantified by Bradford assay (BioAgency Laboratórios, São Paulo, Brazil).

\section{Electrophoresis and immunoblotting}

Kidney samples were run on polyacrylamide minigels. After transfer by electroelution to nitrocellulose membranes (GE Healthcare, Little Chalfont, UK), blots were blocked with 5\% non-fat dry milk in Tris-buffered saline. Blots were then incubated overnight with antibodies against AQP2 (1:1000) and NKCC2 (1:500), as well as 
against V1a and V2 (1:1000 for both), all of which were obtained from Santa Cruz Biotechnology (Dallas, Texas, USA). The labeling was visualized with a horseradish peroxidase-conjugated secondary antibody (antigoat, 1:10 000; Sigma Chemical) and enhanced chemiluminescence (ECL) detection (Amersham Pharmacia Biotech, Piscataway, New Jersey, USA).

\section{Proteins}

We scanned the ECL films with an imaging system (Alliance 4.2; UVItec, Cambridge, UK). We then used densitometry to perform a quantitative analysis of the antibodies, normalizing the bands to actin expression.

\section{Light microscopy}

Four micrometer histological sections of kidney tissue were stained with H\&E and examined under light microscopy. In 40-60 grid fields $\left(0.245 \mathrm{~mm}^{2}\right.$ each; magnification, $\left.\times 400\right)$, we graded the proportional renal damage (tubular epithelial swelling, vacuolar degeneration, necrosis, and desquamation) as follows: $0,<5 \%$; I, 5-25\%; II, 26-50\%; III, 51-75\%; and IV, $>75 \%$. To minimize bias in the morphometric analysis, the observer was blinded to the treatment groups. The mean scores were calculated by animal and by group.

\section{Statistical analysis}

We analyzed physiological parameters across groups and over time with GraphPad Prism V.5.03 for Windows (GraphPad Software, San Diego, California, USA), using one-way analysis of variance followed by the Student-Newman-Keuls test. The results are presented as mean \pm SE. For all analyses, values of $\mathrm{p}<0.05$ were considered statistically significant.

\section{RESULTS}

\section{Terlipressin and LRS reduce mortality in HS}

The mean volume of blood withdrawn was similar among the experimental groups, averaging $60 \%$ of the estimated total blood volume (shock-only group, $1083 \pm 124 \mathrm{~mL}$; shock+LRS group, $1162 \pm 203 \mathrm{~mL}$; and shock+Terli group, $1011 \pm 215 \mathrm{~mL}$ ). By T120, the number of deaths was significantly higher in the shock-only group than in the other groups (6 deaths at a mean of $41 \pm 15$ min after shock $30, p=0.0007)$. In the shock+Terli group, only one animal died (at $80 \mathrm{~min}$ after shock30).

\section{Terlipressin and LRS partially restore blood pressure after HS}

As can be seen in table 1 , both treatments were able to partially restore MAP at T30, T60, and T120.

\section{Terlipressin protects glomerular filtration in HS}

As was expected, HS resulted in a decrease in glomerular filtration, as estimated by measuring creatinine clearance (figure 1). As was also expected, creatinine clearance was markedly lower in the shock-only group at all of the time points evaluated. Only three of the shock-only pigs were evaluated at T120, and all three of those animals were anuric at that point. At T30 and T60, creatinine clearance was lower in the shock+Terli group than in the shock+LRS group, in which it was comparable to that observed in the sham group (figure 1). However, by T120, that situation had been inverted, creatinine clearance being lower in the shock+LRS group than in the shock+Terli group (figure 1). At T30 and T60, urine volume was significantly lower in the shock-only group than in the other groups. By T120, the urine output of the animals in the shock-only group had dropped to zero. At T30 and T60, the shock+LRS pigs presented higher urine volume than did the shock+Terli pigs.
Table 1 Mean arterial pressure in the various groups at the various time points evaluated

MAP (mm Hg)

Time point

\begin{tabular}{lllllr} 
Group & Baseline & Shock30 & T30 & T60 & \multicolumn{1}{c}{ T120 } \\
\hline Sham & $70.5 \pm 2.4$ & $77.0 \pm 3.7$ & $75.5 \pm 3.1$ & $72.5 \pm 2.3$ & $71 \pm 1.0$ \\
Shock-only & $72.9 \pm 2.8$ & $40.0 \pm 1.1^{\text {a }}$ & $40.0 \pm 2.4^{\mathrm{a}}$ & $49.0 \pm 4.0^{\mathrm{b}}$ & $43.3 \pm 8.6^{\mathrm{c}}$ \\
Shock+LRS & $73.6 \pm 1.2$ & $42.8 \pm 1.3^{\mathrm{a}}$ & $60.0 \pm 2.5^{\mathrm{b}, \mathrm{d}}$ & $58.0 \pm 2.6^{\mathrm{c}}$ & $53.0 \pm 2.2$ \\
Shock+Terli & $70.8 \pm 1.4$ & $41.5 \pm 1.0^{\mathrm{a}}$ & $64.2 \pm 2.2^{\mathrm{b}, \mathrm{d}}$ & $60.1 \pm 3.4^{\mathrm{c}}$ & $56.9 \pm 3.7$ \\
\hline
\end{tabular}

Values are mean \pm SE.

${ }^{a} p<0.001$ vs sham; ${ }^{b} p<0.01$ vs sham; ${ }^{c} p<0.05$ vs sham; ${ }^{d} p<0.05$ vs shock30

MAP, mean arterial pressure; Sham, anesthetized but not subjected to hemorrhagic

shock; Shock+LRS, subjected to hemorrhagic shock and subsequently treated with

LRS at a volume equal to three times that of the blood removed; Shock+Terli,

subjected to hemorrhagic shock and subsequently treated with a $2 \mathrm{mg}$ bolus of terlipressin; Shock30, 30 min after achieving the target MAP (immediately prior to treatment); Shock-only, subjected to hemorrhagic shock and left untreated; T120,

120 min after treatment; T30, 30 min after treatment; T60, 60 min after treatment.

However, there was thereafter an inversion similar to that observed for creatinine clearance, urine volume at T120 being higher in the shock+Terli group than in the shock+LRS group (figure 1).

\section{Terlipressin protects tubular function in HS}

The shock-only pigs presented hyponatremia at T60 and hypernatremia at T120. Throughout the study period, serum sodium levels were lower in the shock+LRS and shock+Terli groups than in the sham group (table 2). It is of note that, at T120, the hyponatremia was more pronounced in the shock+Terli group than in the shock+LRS group. As expected, the shock-only group presented higher serum levels of potassium at all of the time points evaluated, an effect that was mitigated in the shock +LRS and shock+Terli groups (table 2). At T60, the shock +LRS and shock+Terli groups presented serum chloride levels that were lower than those observed for the sham group. By T30, the shock-only pigs had developed hyperphosphatemia, although the condition did not persist to T60 or T120. In the shock+LRS group, post-treatment serum phosphorus levels were similar to those observed for the sham group. At T30 and T60, serum levels of phosphorus were higher in the shock +Terli group than in the shock+LRS group. The shock-only pigs also presented hypermagnesemia throughout the study period. At T30 and T60, serum levels of magnesium were lower in the shock+LRS group than in the shock-only group, as well as being higher in the shock+Terli group than in the shock +LRS group.

Table 2 shows the urinary excretion of ions and urea, together with urine osmolality. At shock30, urinary excretion of sodium and potassium was lower in the shock-only, shock+LRS, and shock+Terli groups than in the sham group. At all time points evaluated, urinary excretion of sodium, potassium, chloride, magnesium, phosphorus, and urea was lowest in the shock-only group. At T30, urinary excretion of sodium, potassium, chloride, magnesium, phosphorus, and urea was markedly higher in the shock+LRS group than in the other groups. However, at T60, urinary excretion of all analyzed ions and of urea were lower in the shock+LRS group than in the sham and shock +Terli groups. In fact, at T120, the shock+LRS pigs continued to show marginally decreased urinary excretion of sodium, potassium, chloride, magnesium, urea, and phosphorus in comparison with the sham and shock+Terli pigs. In the shock+Terli 


\section{Creatinine} clearance

A

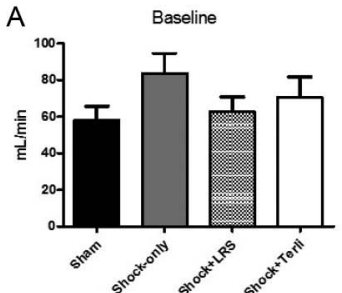

B

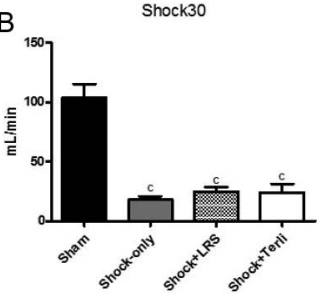

C

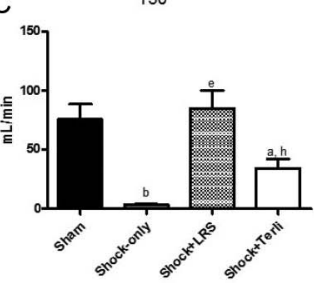

D

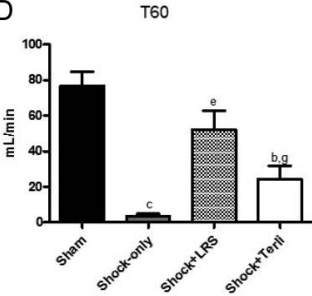

E

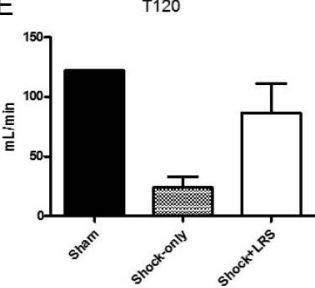

Urinary

volume
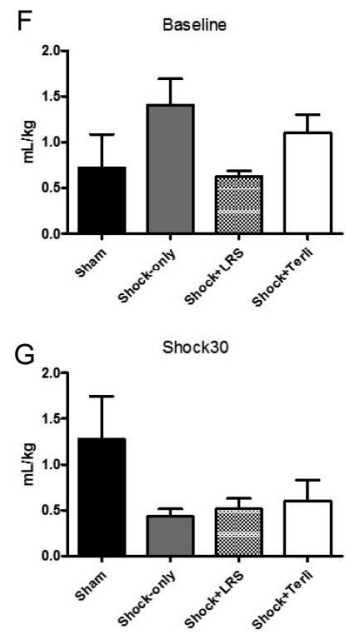

$\mathrm{H}$
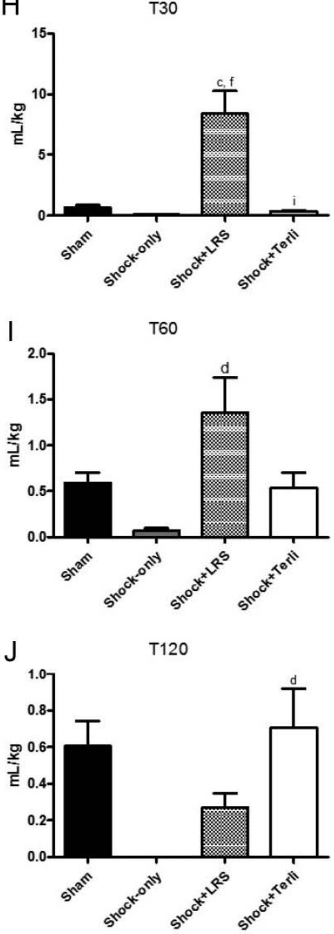

Figure 1 Creatinine clearance and urine volume in the sham, shock-only, shock+LRS, and shock+Terli groups at baseline, Shock, T30, T60, and T120. ${ }^{a} p<0.05$ vs sham; ${ }^{b} p<0.01$ vs sham; ${ }^{c} p<0.001$ vs sham; ${ }^{d} p<0.05$ vs shock-only; ${ }^{e} p<0.01$ vs shock-only; ${ }^{f}<<0.001$ vs shock-only; ${ }^{g} p<0.05$ vs shock+LRS; ${ }^{h} p<0.01$ vs shock+LRS; $p<0.001$ vs shock+LRS.

group, urinary excretion of sodium, potassium, chloride, and urea remained constant at T30 and T60, although that of phosphorus was elevated at T120. At T30 and T60, urine osmolality was lower in the shock+LRS and shock+Terli groups than in the sham group.

At T60, renal expression of AQP2 was significantly lower in shock-only pigs than in sham pigs $(52.5 \pm 3.2 \%$ vs $100 \pm 1.1 \%$, $\mathrm{p}<0.001$ ), as well as being significantly lower in shock+LRS pigs than in sham and shock+Terli pigs $(38.7 \pm 6.6 \%$ vs 100 $\pm 1.1 \%$ and $82.5 \pm 7.8 \%, \mathrm{p}<0.001$ for both; figure 2). At T120, AQP2 expression was significantly lower in the shock-only and shock+LRS groups than in the sham and shock+Terli groups

$(22.5 \pm 2.5 \%$ and $43.3 \pm 12 \%$ vs $96.7 \pm 3.3 \%$ and $107.5 \pm 4.8 \%$, $\mathrm{p}<0.001$ for both; figure 2).

At T60, NKCC2 protein expression was significantly lower in the kidneys of shock-only pigs than in those of sham, shock $+\mathrm{LRS}$, and shock+Terli pigs $(38.7 \pm 18.1 \%$ vs $99.3 \pm 0.7 \%, 100$ $\pm 0.8 \%$, and $90 \pm 6.1 \%, \mathrm{p}<0.01$ for all; figure 2 ), indicating that terlipressin and LRS both restore that expression after HS. At T120, NKCC2 expression was still lower in the shock-only group than in the sham and shock+Terli groups $(27.7 \pm 1.7 \%$ vs $101.7 \pm 1.7 \%$ and $92.5 \pm 12.5 \%, \mathrm{p}<0.01$ for both), as well as being quite low in the shock+LRS group $(50 \pm 20.8 \%, \mathrm{p}<0.05$ vs sham and shock+Terli; figure 2 ).

\section{Terlipressin protects tubular damage in HS}

Figure 3 shows that renal tubular damage (acute tubular necrosis) was more extensive in the shock-only group than in the sham, shock+LRS, and shock+Terli groups $(0.45 \pm 0.1$ vs 0.05 $\pm 0.00,0.16 \pm 0.24$, and $0.10 \pm 0.02, \mathrm{p}<0.01$ for all).

\section{Expression of V1a and V2}

At T60, protein expression of V1a was higher in the shock-only group than in the sham, shock+LRS, and shock+Terli groups $(130 \pm 6.8 \%$ vs $93.3 \pm 4.4 \%, 80.0 \pm 4.6 \%$, and $107.5 \pm 4.8 \%$, $\mathrm{p}<0.01$ for all), as well as being higher in the shock+Terli group than in the shock+LRS group $(\mathrm{p}<0.01$; figure 4$)$. At T120, V1a expression was still higher in the shock-only group than in the sham and shock+LRS groups $(112.3 \pm 1.4 \%$ vs 100 $\pm 0.6 \%$ and $74 \pm 6.7 \%, p<0.05$ for both), although it was also quite high in the shock+Terli group $(109.8 \pm 2.0 \%, \mathrm{p}<0.001$ vs shock+LRS; figure 4).

At T60, protein expression of V2 was higher in the shockonly group than in the sham, shock+LRS, and shock+Terli groups $(144.3 \pm 8.1 \%$ vs $103 \pm 2.4 \%, 103.3 \pm 2.7 \%$, and 117.0 $\pm 12.1 \%, \mathrm{p}<0.05$ for all; figure 4$)$. At T120, the relationship between the shock-only group and the other groups remained the same, V2 protein expression continuing to be higher in the shock-only group than in the sham, shock+LRS, and shock + Terli groups $(121.7 \pm 4.4 \%$ vs $98.3 \pm 4.4 \%, 89.6 \pm 5.5 \%$, and $96.6 \pm 1.9 \%, \mathrm{p}<0.01$ for all; figure 4$)$.

\section{DISCUSSION}

The most important finding of the present study was that terlipressin administration appears to be protective of renal function in HS. That is in keeping with previous reports showing that terlipressin is protective of other organs during HS. ${ }^{22} 23$ One of the main consequences of severe traumatic injury is multiorgan failure, and AKI (of any cause) can lead to acute renal failure. Among trauma cases, the incidence of multiorgan failure can be as high as $17 \% .^{24}$ There are few if any effective therapeutic measures that can prevent or mitigate the deleterious consequences of traumatic injury. Until recently, the strategy thought to be optimal for the treatment of HS was volume crystalloid resuscitation, typically performed during prehospital care. However, that strategy can lead to volume overload, which has been recognized as an independent predictor of mortality in intensive care unit patients. ${ }^{25-27}$ In the previously mentioned parallel study of HS in swine, ${ }^{22}$ we found that resuscitation with LRS-albeit effective in decreasing mortality, recovering MAP, decreasing serum levels of lactate, and increasing the cardiac index-resulted in a significant increase in intracranial pressure and a significant decrease in cerebral perfusion pressure, as well as a significant increase in the expression of AQP4, which might indicate an increase in brain water content. In addition, resuscitation with LRS can worsen HS-induced pulmonary 
Table 2 Biochemical variables in the various groups at the various time points evaluated in the various groups at the various time points evaluated

\begin{tabular}{|c|c|c|c|c|c|}
\hline \multirow{2}{*}{$\begin{array}{l}\text { Serum } \\
\text { Group }\end{array}$} & \multicolumn{5}{|l|}{ Period } \\
\hline & Baseline & Shock30 & T30 & T60 & T120 \\
\hline \multicolumn{6}{|l|}{$\mathrm{Na}(\mathrm{mEq} / \mathrm{L})$} \\
\hline Sham & $145 \pm 3.1$ & $149 \pm 5.9$ & $144 \pm 4.7$ & $154 \pm 9.2$ & $135 \pm 10.50$ \\
\hline Shock-only & $138 \pm 1.2$ & $141 \pm 5.3$ & $140 \pm 5.7$ & $132 \pm 4.3^{b}$ & $154 \pm 0.00$ \\
\hline Shock+LRS & $136 \pm 2.1$ & $132 \pm 1.8^{\mathrm{a}}$ & $131 \pm 2.2$ & $131 \pm 1.2^{c}$ & $130 \pm 4.70$ \\
\hline Shock+Terli & $138 \pm 2.4$ & $134 \pm 2.9^{\mathrm{a}}$ & $138 \pm 2.7$ & $134 \pm 1.5^{c}$ & $127 \pm 2.90$ \\
\hline \multicolumn{6}{|l|}{$\mathrm{K}(\mathrm{mEq} / \mathrm{L})$} \\
\hline Sham & $4.6 \pm 0.3$ & $4.7 \pm 0.2$ & $4.6 \pm 0.2$ & $5.1 \pm 0.3$ & $4.8 \pm 0.10$ \\
\hline Shock-only & $4.8 \pm 0.2$ & $5.9 \pm 0.4^{a}$ & $6.4 \pm 0.5^{b}$ & $6.0 \pm 0.9$ & $7.7 \pm 0.00$ \\
\hline Shock+LRS & $4.2 \pm 0.1$ & $6.4 \pm 0.4^{a}$ & $4.5 \pm 0.2^{f}$ & $5.1 \pm 0.1$ & $5.9 \pm 0.30$ \\
\hline Shock+Terli & $4.3 \pm 0.1$ & $5.3 \pm 0.2^{g}$ & $5.4 \pm 0.2^{d}$ & $5.4 \pm 0.2$ & $5.6 \pm 0.40$ \\
\hline \multicolumn{6}{|l|}{$\mathrm{Cl}(\mathrm{mEq} / \mathrm{L})$} \\
\hline Sham & $108 \pm 2.1$ & $111 \pm 4.6$ & $109 \pm 4.4$ & $115 \pm 7.7$ & $104 \pm 15.5$ \\
\hline Shock-only & $105 \pm 2.4$ & $107 \pm 4.3$ & $106 \pm 4.7$ & $107 \pm 5.2$ & $117 \pm 0.0$ \\
\hline Shock+LRS & $100 \pm 1.6$ & $100 \pm 1.7$ & $94 \pm 4.7$ & $99 \pm 1.0^{\mathrm{a}}$ & $94 \pm 4.60$ \\
\hline Shock+Terli & $104 \pm 2.2$ & $99 \pm 2.2$ & $102 \pm 2.1$ & $96 \pm 3.1^{b}$ & $91 \pm 3.20$ \\
\hline \multicolumn{6}{|l|}{$\mathrm{Mg}(\mathrm{mg} / \mathrm{dL})$} \\
\hline Sham & $1.9 \pm 0.14$ & $1.7 \pm 0.10$ & $1.7 \pm 0.10$ & $1.7 \pm 0.14$ & $1.8 \pm 0.10$ \\
\hline Shock-only & $1.8 \pm 0.08$ & $2.1 \pm 0.08$ & $2.2 \pm 0.11^{\mathrm{a}}$ & $2.1 \pm 0.17$ & $2.8 \pm 0.00$ \\
\hline Shock+LRS & $1.8 \pm 0.10$ & $2.3 \pm 0.13$ & $1.5 \pm 0.08^{f}$ & $1.5 \pm 0.09^{d}$ & $1.7 \pm 0.12$ \\
\hline Shock+Terli & $1.9 \pm 0.07$ & $2.1 \pm 0.12$ & $1.9 \pm 0.09^{h}$ & $2.1 \pm 0.10^{\mathrm{h}}$ & $2.0 \pm 0.22$ \\
\hline \multicolumn{6}{|l|}{$P(\mathrm{mg} / \mathrm{dL})$} \\
\hline Sham & $9.3 \pm 1.00$ & $9.4 \pm 0.91$ & $9.7 \pm 0.74$ & $9.9 \pm 0.91$ & $10 \pm 2.00$ \\
\hline Shock-only & $8.8 \pm 0.52$ & $10.6 \pm 0.59$ & $12.2 \pm 0.91^{\mathrm{a}}$ & $10.7 \pm 1.00$ & $13 \pm 0.00$ \\
\hline Shock+LRS & $9.3 \pm 0.48$ & $12.2 \pm 0.85$ & $8.1 \pm 0.42^{f}$ & $8.3 \pm 0.51$ & $9.7 \pm 0.90$ \\
\hline Shock+Terli & $8.5 \pm 0.40$ & $10.1 \pm 0.56$ & $10.8 \pm 0.47^{d}$ & $12.0 \pm 0.55^{\mathrm{h}}$ & $11.6 \pm 1.8$ \\
\hline \multicolumn{6}{|l|}{ Urea (mg/dL) } \\
\hline Sham & $20.2 \pm 2.33$ & $21.8 \pm 2.31$ & $23.1 \pm 2.93$ & $23.5 \pm 2.56$ & $17.0 \pm 2.00$ \\
\hline Shock-only & $20.4 \pm 2.33$ & $25.4 \pm 2.45$ & $27.4 \pm 2.25$ & $24.0 \pm 0.45$ & $31.0 \pm 0.00$ \\
\hline Shock+LRS & $19.1 \pm 2.01$ & $25.0 \pm 2.43$ & $21.3 \pm 2.01$ & $33.6 \pm 11.46$ & $26.0 \pm 4.00$ \\
\hline Shock+Terli & $26.5 \pm 2.76$ & $33.0 \pm 3.10$ & $35.1 \pm 3.22^{\mathrm{a}, \mathrm{h}}$ & $37.2 \pm 3.20$ & $41.1 \pm 5.10$ \\
\hline \multirow{2}{*}{$\begin{array}{l}\text { Urine } \\
\text { Group }\end{array}$} & \multicolumn{5}{|l|}{ Period } \\
\hline & Baseline & Shock30 & T30 & T60 & T120 \\
\hline \multicolumn{6}{|c|}{ UNaV (mEq/period) } \\
\hline Sham & $0.5 \pm 0.1$ & $1.2 \pm 0.7$ & $0.6 \pm 0.3$ & $0.6 \pm 0.2$ & $0.8 \pm 0.3$ \\
\hline Shock-only & $0.7 \pm 0.1$ & $0.6 \pm 0.3$ & $0.2 \pm 0.1$ & $0.2 \pm 0.1$ & 0 \\
\hline Shock+LRS & $0.4 \pm 0.1$ & $0.4 \pm 0.2$ & $20.5 \pm 4.7^{c, e}$ & $2.2 \pm 0.8$ & $0.1 \pm 0.0$ \\
\hline Shock+Terli & $0.5 \pm 0.1$ & $0.2 \pm 0.1$ & $0.2 \pm 0.0^{\mathrm{i}}$ & $0.5 \pm 0.3$ & $0.3 \pm 0.1$ \\
\hline \multicolumn{6}{|c|}{ UKV (mEq/period) } \\
\hline Sham & $1.8 \pm 0.5$ & $4.5 \pm 1.4$ & $2.7 \pm 0.8$ & $2.7 \pm 0.5$ & $2.6 \pm 1.7$ \\
\hline Shock-only & $3.7 \pm 1.1$ & $1.5 \pm 0.4^{\mathrm{a}}$ & $0.2 \pm 0.1$ & $0.1 \pm 0.0^{\mathrm{a}}$ & 0 \\
\hline Shock+LRS & $1.9 \pm 0.3$ & $1.8 \pm 0.3^{a}$ & $12.7 \pm 5.7^{\mathrm{c}, \mathrm{f}}$ & $2.3 \pm 0.6^{d}$ & $0.6 \pm 0.2$ \\
\hline Shock+Terli & $2.2 \pm 0.3$ & $1.8 \pm 0.8^{\mathrm{a}}$ & $0.8 \pm 0.2^{\mathrm{h}}$ & $0.9 \pm 0.3$ & $1.5 \pm 0.7$ \\
\hline \multicolumn{6}{|c|}{ UCIV (mEq/period) } \\
\hline Sham & $2.2 \pm 1.2$ & $4.3 \pm 1.7$ & $1.9 \pm 0.5$ & $1.7 \pm 0.3$ & $1.5 \pm 0.8$ \\
\hline Shock-only & $3.9 \pm 0.9$ & $1.6 \pm 0.4$ & $0.3 \pm 0.2$ & $0.2 \pm 0.1$ & 0 \\
\hline Shock+LRS & $1.5 \pm 0.3$ & $1.4 \pm 0.4$ & $19.5 \pm 4.9^{b, e}$ & $3.7 \pm 1.3$ & $0.4 \pm 0.2$ \\
\hline Shock+Terli & $2.7 \pm 0.6$ & $1.3 \pm 0.6$ & $0.6 \pm 0.2^{\mathrm{i}}$ & $0.6 \pm 0.2$ & $1.1 \pm 0.5$ \\
\hline \multicolumn{6}{|c|}{ UMgV (mg/period) } \\
\hline Sham & $3.2 \pm 1.3$ & $1.8 \pm 0.4$ & $1.5 \pm 0.9$ & $1.2 \pm 0.4$ & $0.7 \pm 0.5$ \\
\hline Shock-only & $6.3 \pm 1.5$ & $1.2 \pm 0.2$ & $0.1 \pm 0.4$ & $0.3 \pm 0.1$ & 0 \\
\hline Shock+LRS & $3.7 \pm 0.7$ & $2.2 \pm 0.6$ & $9.1 \pm 1.6^{b, f}$ & $2.2 \pm 0.7$ & $0.4 \pm 0.2$ \\
\hline Shock+Terli & $5.2 \pm 0.9$ & $1.6 \pm 0.5$ & $2.6 \pm 1.0^{i}$ & $2.0 \pm 0.6$ & $3.3 \pm 0.8$ \\
\hline \multicolumn{6}{|c|}{ UPV (mg/period) } \\
\hline Sham & $1.7 \pm 1.4$ & $11.3 \pm 6.3$ & $7.4 \pm 3.8$ & $7.9 \pm 3.3$ & $3.2 \pm 1.6$ \\
\hline
\end{tabular}


Table 2 Continued

\begin{tabular}{|c|c|c|c|c|c|}
\hline \multirow{2}{*}{$\begin{array}{l}\text { Urine } \\
\text { Group }\end{array}$} & \multicolumn{5}{|l|}{ Period } \\
\hline & Baseline & Shock30 & T30 & T60 & T120 \\
\hline Shock-only & $4.3 \pm 2.3$ & $4.7 \pm 2.1$ & $1.2 \pm 0.8$ & $0.2 \pm 0.2$ & 0 \\
\hline Shock+LRS & $1.9 \pm 1.2$ & $7.8 \pm 2.5$ & $74.1 \pm 20.8^{b, d}$ & $14 \pm 4.6^{d}$ & $3.8 \pm 3.0$ \\
\hline Shock+Terli & $3.3 \pm 1.6$ & $2.4 \pm 1.4$ & $6.1 \pm 3.04^{\mathrm{h}}$ & $7.4 \pm 3.3$ & $14.2 \pm 12.2$ \\
\hline \multicolumn{6}{|c|}{ UureaV (mg/period) } \\
\hline Sham & $184.4 \pm 49.3$ & $371.8 \pm 88.1$ & $223.8 \pm 66.6$ & $210.4 \pm 43.4$ & $162.9 \pm 113.1$ \\
\hline Shock-only & $489.5 \pm 82.9$ & $117 \pm 22.9^{\mathrm{a}}$ & $18.3 \pm 7.9$ & $15.5 \pm 2.2^{\mathrm{a}}$ & 0 \\
\hline Shock+LRS & $203.7 \pm 31.1$ & $140.9 \pm 280.6^{a}$ & $468.5 \pm 98.8^{\mathrm{a}, \mathrm{e}}$ & $193.4 \pm 48.6^{d}$ & $64.6 \pm 28.2$ \\
\hline Shock+Terli & $428.3 \pm 94.3$ & $194.9 \pm 77.8$ & $103.3 \pm 24.4^{i}$ & $87.6 \pm 27.9$ & $282.6 \pm 103.6$ \\
\hline \multicolumn{6}{|c|}{ Uosm (m0sm/kg) } \\
\hline Sham & $735.8 \pm 96.1$ & $748.7 \pm 102.3$ & $739 \pm 85.7$ & $734.6 \pm 90.6$ & $617.5 \pm 59.5$ \\
\hline Shock-only & $563.4 \pm 95.7$ & $592.6 \pm 65.5$ & $446.5 \pm 154.5^{a}$ & $541.3 \pm 92.2$ & $793 \pm 0.0$ \\
\hline Shock+LRS & $621.0 \pm 39.6$ & $629.3 \pm 37.3$ & $368.6 \pm 15.5^{c}$ & $464.7 \pm 27.8^{b}$ & $462.8 \pm 25.5$ \\
\hline Shock+Terli & $659.0 \pm 46.8$ & $693.5 \pm 45.9$ & $593.4 \pm 54.4^{b}$ & $522 \pm 39.5^{a}$ & $653 \pm 91.2$ \\
\hline \multicolumn{6}{|c|}{$\begin{array}{l}\text { Values are mean } \pm S E \text {. } \\
{ }^{a} p<0.05 \text { vs sham; }{ }^{b} p<0.01 \text { vs sham; }{ }^{c} p<0.001 \text { vs sham; }{ }^{d} p<0.05 \text { vs shock-only; }{ }^{e} p<0.01 \text { vs shock-only; }{ }^{f} p<0.001 \text { vs shock-only; }{ }^{g} p<0.05 \text { vs shock+LRS; }{ }^{h} p<0.01 \text { vs shock+LR; }{ }^{i} p<0.001 \\
\text { vs shock+LRS. } \\
\text { Sham, anesthetized but not subjected to hemorrhagic shock; Shock+LRS, subjected to hemorrhagic shock and subsequently treated with LRS at a volume equal to three times that of } \\
\text { the blood removed; Shock+Terli, subjected to hemorrhagic shock and subsequently treated with a } 2 \text { mg bolus of terlipressin; Shock30, } 30 \text { min after achieving the target MAP } \\
\text { (immediately prior to treatment); Shock-only, subjected to hemorrhagic shock and left untreated; T120, } 120 \text { min after treatment; T30, } 30 \text { min after treatment; T60, } 60 \text { min after } \\
\text { treatment; UCIV, urinary excretion of chloride; UKV, urinary excretion of potassium; UMgV, urinary excretion of magnesium; UNaV, urinary excretion of sodium; Uosm, urine osmolality; } \\
\text { UureaV, urinary excretion of urea. }\end{array}$} \\
\hline
\end{tabular}
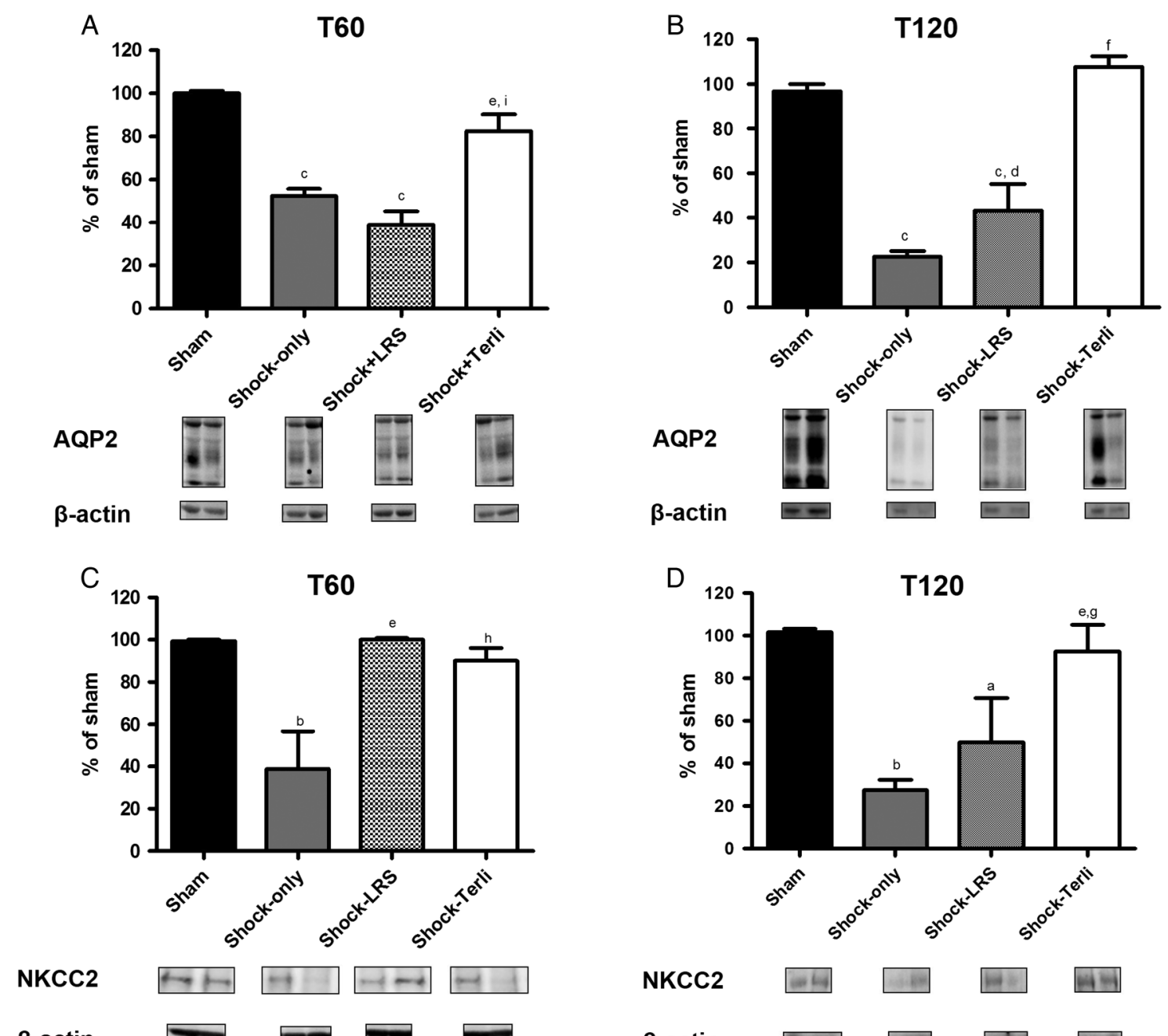

$\beta$-actin
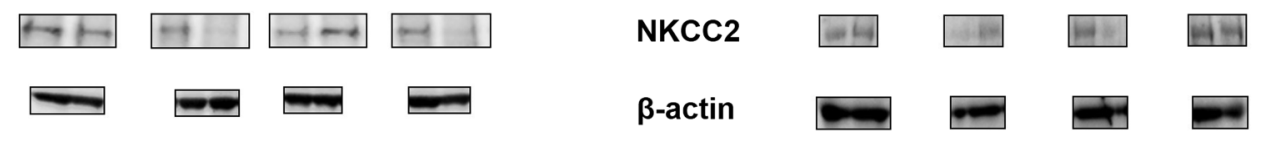

Figure 2 Expression of aquaporin 2 and NKCC2. Densitometry and immunoblotting in the sham, shock-only, shock+LRS and shock+Terli groups at T60 and T120. ${ }^{a} p<0.05$ vs sham; ${ }^{b} p<0.01$ vs sham; ${ }^{c} p<0.001$ vs sham; ${ }^{d} p<0.05$ vs shock-only; ${ }^{e} p<0.01$ vs shock-only; ${ }^{f} p<0.001$ vs shock-only; ${ }^{g} p<0.05$ vs shock+LRS; ${ }^{h} p<0.01$ vs shock+LRS; $i^{p}<0.001$ vs shock+LRS. 



Figure 3 Tubular injury in porcine kidney tissue. Representative photomicrographs of kidney tissue samples from the sham, shock-only, shock+LRS, and shock+Terli groups at T60. Magnification, $\times 400$. Bar graph of tubular injury scores. ${ }^{a} p<0.001$ vs sham; ${ }^{b}<<0.01$ vs shock-only.

hyperpermeability, inflammation, acute lung injury, and acute respiratory distress syndrome. ${ }^{28}$

Lee et $a l^{29}$ subjected mice to HS by amputating $80 \%$ of the tail, a model that mimics what happens in a human victim of bleeding. At $30 \mathrm{~min}$ after the onset of bleeding, the animals received a mixture of plasma and LRS, after which they received terlipressin, vasopressin, or high-volume resuscitation with LRS. The authors found that, although terlipressin and vasopressin restored MAP, terlipressin sustained a satisfactory MAP for a longer period. Vasopressin and terlipressin were also found to decrease serum lactate levels and pro-inflammatory cytokine production, as well as to reduce lung injury and mortality. ${ }^{29}$

Even after fluid resuscitation, HS-induced AKI is observed in $\sim 30 \%$ of patients admitted to intensive care units. ${ }^{30}$ In the present study, we observed extremely high mortality in the untreated animals, demonstrating the severity of a situation in which there is high blood loss without timely administration of appropriate treatment. We found that administration of terlipressin and high-volume resuscitation with LRS both decreased mortality in this porcine model of HS.

As previously mentioned, creatinine clearance was highest in the shock+LRS group at T30 and T60, whereas, at T120, it was higher in the shock+Terli group than in the shock+LRS group. That suggests that administration of terlipressin has longerlasting beneficial effects than does high-volume resuscitation with LRS.

In the present study, we found that HS induced hyponatremia by $\mathrm{T} 60$, an effect that was probably attributable to vasopressin release. Both treated groups also presented hyponatremia throughout the study period, although it was more pronounced 

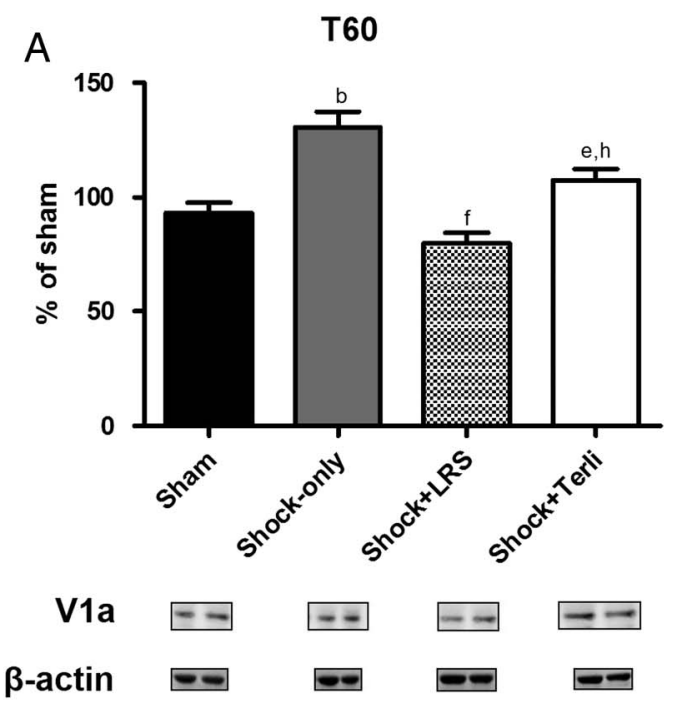

T60

C

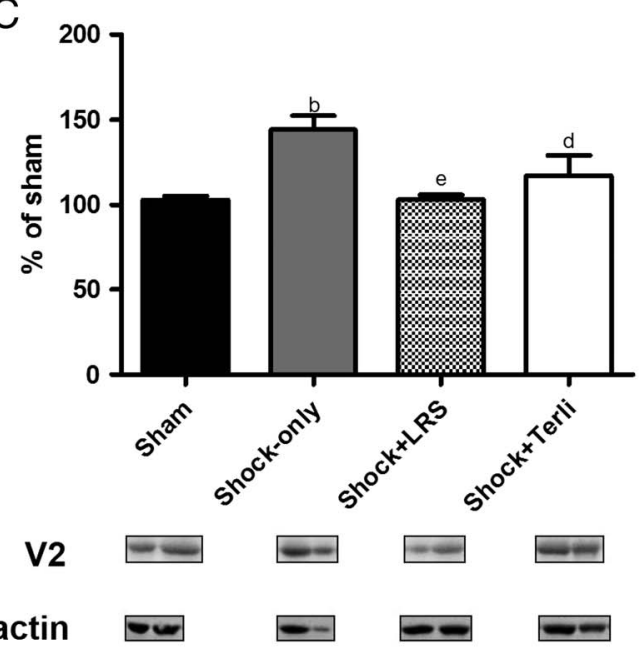

B

T120

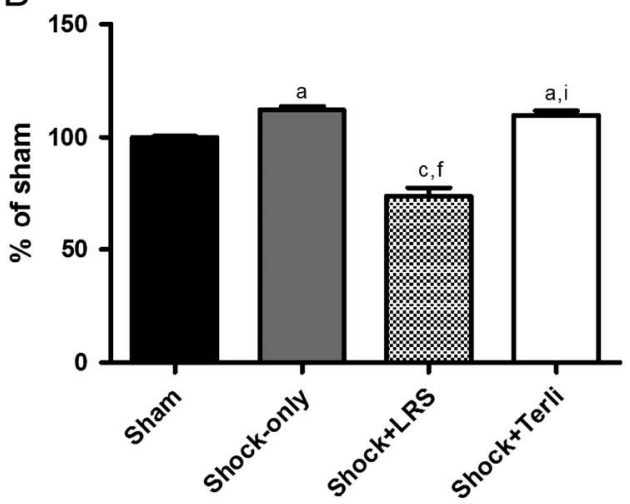

V1a

$\beta$-actin

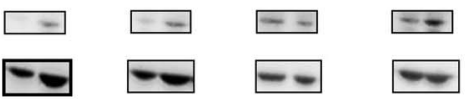

$\mathrm{T} 120$

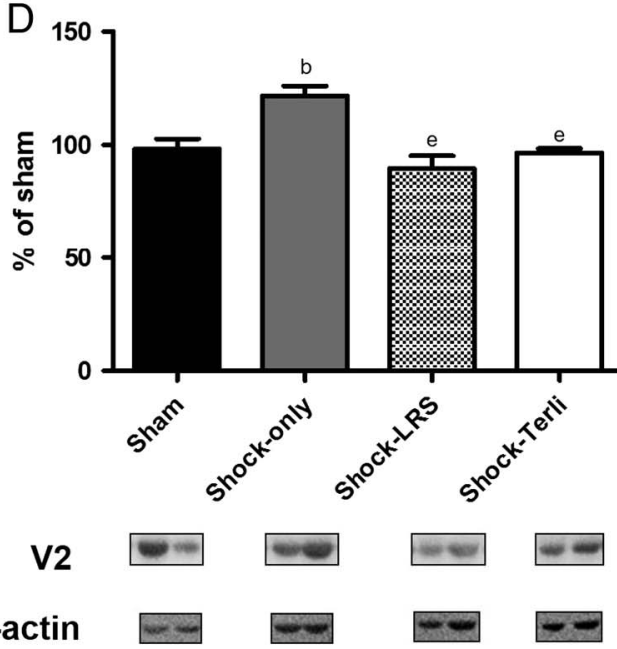

Figure 4 Expression of the vasopressin receptors V1a and V2. Densitometry and immunoblotting in the sham, shock-only, shock+LRS, and shock +Terli groups at T60 and T120. ${ }^{a} p<0.05$ vs sham; ${ }^{b} p<0.01$ vs sham; ${ }^{C} p<0.001$ vs sham; ${ }^{d} p<0.05$ vs shock-only; ${ }^{e} p<0.01$ vs shock-only; ${ }^{f} p<0.001$ vs shock-only; ${ }^{g} p<0.05$ vs shock+LRS; ${ }^{h} p<0.01$ vs shock+LRS; ${ }^{i} p<0.001$ vs shock+LRS.

in the shock+Terli group at T120. In the shock+LRS group, that could be attributed to hemodilution after volume expansion, shock-induced vasopressin release, and increased urinary excretion of sodium. In the shock+Terli group, the failure of the treatment to reverse the HS-induced hyponatremia might be attributable to the interaction between terlipressin and the vasopressin receptors. Yim et $a l^{31}$ analyzed patients with variceal bleeding treated with terlipressin and observed a significant reduction in serum sodium levels. However, after the discontinuation of terlipressin, normal sodium levels were gradually re-established. ${ }^{31}$ According to those authors, one possible explanation for the hyponatremia is that terlipressin, in addition to its vasoconstrictor effect via the V1a receptor, also acts on the V2 receptor, increasing water reabsorption via AQP2 and decreasing the serum levels of sodium. In the present study, the shock-only group presented hyperkalemia, as was expected, given that AKI decreases urinary excretion of potassium and that HS is known to cause acidemia. ${ }^{32}$

Acute magnesium deficiency has been shown to increase production of pro-inflammatory cytokines in rats. ${ }^{33}$ At some of the time points evaluated, our shock+LRS pigs presented hypochloremia and hypomagnesemia, both of which might have been provoked by the volume expansion, which can increase urinary excretion of chloride and magnesium. It of note that, although the shock+LRS pigs showed higher urinary excretion of sodium, potassium, chloride, magnesium, phosphorus, and urea at T30, that was no longer the case at T120, when all of those values were lower in the shock+LRS pigs than in the sham and shock+Terli pigs.

As previously mentioned, we observed acute tubular necrosis in the shock-only pigs at T60. We also found that administration of terlipressin and high-volume resuscitation with LRS both protected renal tissue against HS-induced tubular necrosis. That effect is likely attributable to the ability of both treatments maintain renal perfusion pressure.

In the setting of HS, the pituitary gland releases vasopressin, the V2 receptor of which increases the insertion of AQP2 into the apical membrane of cells in the distal tubules and collector, thereby increasing permeability to water. ${ }^{34}$ In addition, vasopressin has been shown to increase the expression of NKCC2, which is expressed in the thick ascending limb of Henle's loop. ${ }^{35}$ Furthermore, AKI is known to downregulate expression 
of NKCC2 and AQP2. ${ }^{10}{ }^{36}$ In a recent study, we demonstrated that sepsis-induced AKI downregulates AQP2 and NKCC2 expression in the renal tissue of rats. ${ }^{9}$ In the present study, treatment with terlipressin restored normal expression of NKCC2 and AQP2 after HS, although we did not observe any significant reversal of the HS-induced decrease in urine osmolality. These data suggest that administration of terlipressin is more effective than is high-volume resuscitation with LRS in protecting the expression of sodium and water protein transporters in the renal tubules.

As previously stated, V1a receptors are densely distributed in vascular smooth muscle cells ${ }^{11}$ and V2 receptors are located mainly in the kidney, stimulating water reabsorption. ${ }^{12}$ The coordinated physiological response resulting from the interaction between those two types of receptors promotes vasoconstriction and water retention, preserving circulating volume in the setting of HS. Therefore, as expected, we found that our shock-only pigs showed high expression of V1a and V2 at T60 and T120. An unexpected finding was that there was a decrease in V1a expression in the shock+LRS pigs at T120. It has been shown that even norepinephrine-induced vasoconstriction of the afferent arteriole can be abolished by treatment with vasopressin if the V1-type receptors are blocked. ${ }^{13}$ However, further studies are needed in order to clarify these aspects.

In conclusion, we have demonstrated that administration of terlipressin is equal to high-volume resuscitation with LRS in treating the adverse renal effects of HS, although the risk of fluid overload and its consequences is greater when the latter treatment is applied. Therefore, terlipressin might be useful for preventing HS-induced AKI and could represent an alternative to high-volume resuscitation in prehospital trauma care.

Contributors LUC contributed to conception and design, collection and/or assembly of data, data analysis and interpretation, manuscript writing, final approval of manuscript; KKI contributed to collection and/or assembly of data, data analysis, and interpretation; DAO contributed to collection and/or assembly of data; data analysis, and interpretation; TRS contributed to collection and/or assembly of data, data analysis, and interpretation; RAV contributed to collection and/or assembly of data; ESB contributed to collection and/or assembly of data; L-MSM contributed to conception and design; LA contributed to conception and design, data analysis and interpretation, manuscript writing, final approval of manuscript.

Funding This study was supported by the Fundação de Amparo à Pesquisa do Estado de São Paulo (FAPESP, São Paulo Research Foundation; grant number 2011/ 00348-1). LUC, KKI, and TRS are the recipients of FAPESP grants (grant numbers 2012/04128-9, 2013/09179-3, and 2012/03025-1, respectively); and LA is the recipient of a grant from the Brazilian Conselho Nacional de Desenvolvimento Científico e Tecnológico (CNPq, National Council for Scientific and Technological Development; grant number 302835/2009-1).

Competing interests None declared.

Provenance and peer review Not commissioned; externally peer reviewed.

Open Access This is an Open Access article distributed in accordance with the Creative Commons Attribution Non Commercial (CC BY-NC 4.0) license, which permits others to distribute, remix, adapt, build upon this work non-commercially, and license their derivative works on different terms, provided the original work is properly cited and the use is non-commercial. See: http://creativecommons.org/ licenses/by-nc/4.0/

\section{REFERENCES}

1 Sociedade Brasileira de Atendimento Integrado ao Traumatizado, 0 que é Trauma? http://www.sbait.org.br/trauma.php (accessed 14 Apr 2014).

2 Irineu Dias, Clínica Médica, TDAH X Trauma. http://tdah.com.br/paginas/gaetah/ Boletim3.htm (accessed 14 Apr 2014).

3 Relatório Anual de Acidentes de Trânsito Fatais - 2012, Companhia de Engenharia de Tráfego; São Paulo - Brazil. http://cetsp.com.br/media/217927/anualfatais2012. pdf (accessed 14 Apr 2014).

4 Fatos e Estatísticas de Acidentes de Trânsito em São Paulo - 2011, Companhia de Engenharia de Tráfego; São Paulo-Brazil. http://www.cepsp.com.br/media/186829/ fa\%20e\%20est\%202011.pdf (accessed 14 Apr 2014).
5 New York City Department of Transportation, 2012, March 18 - news release. http://www.nyc.gov/html/dot/htm/pr2012/prindex_en_0_shtml (accessed 14 Apr 2014).

6 Wang Z, Rabb H, Haq M, Shull GE, Soleimani M. A possible molecular basis of natriuresis during ischemic-reperfusion injury in the kidney. J Am Soc Nephrol 1998;9:605-13.

7 Bonventre JV, Yang L. Cellular pathophysiology of ischemic acute kidney injury. J Clin Invest 2011;121:4210-21.

8 Molitoris BA. Therapeutic translation in acute kidney injury: the epithelial/ endothelial axis. J Clin Invest 2014;124:2355-63.

9 Rodrigues CE, Sanches TR, Volpini RA, Shimizu MH, Kuriki PS, Camara NO, Seguro AC, Andrade L. Effects of continuous erythropoietin receptor activator in sepsis-induced acute kidney injury and multi-organ dysfunction. PLOS ONE 2012;7: e29893.

10 Gong H, Wang W, Kwon TH, Jonassen T, Li C, Ring T, FrøkiAEr J, Nielsen S. EPO and alpha-MSH prevent ischemia/reperfusion-induced down-regulation of AQPs and sodium transporters in rat kidney. Kidney Int 2004;66:683-95.

11 Koshimizu TA, Nakamura K, Egashira N, Hiroyama M, Nonoguchi H, Tanoue A. Vasopressin V1a and V1b receptors: from molecules to physiological systems. Physiol Rev 2012;92:1813-64.

12 Wilson JL, Miranda CA, Knepper MA. Vasopressin and the regulation of aquaporin-2. Clin Exp Nephrol 2013;17:751-64.

13 Tamaki T, Kiyomoto K, He H, Tomohiro A, Nishiyama A, Aki Y, Kimura S, Abe Y. Vasodilation induced by vasopressin V2 receptor stimulation in afferent arterioles. Kidney Int 1996;49:722-9.

14 Moore-Olufemi SD, Xue H, Attuwaybi BO, Fischer U, Harari Y, Oliver DH, Weisbrodt $\mathrm{N}$, Allen SJ, Moore FA, Stewart R, et al. Resuscitation-induced gut edema and intestinal dysfunction. J Trauma 2005;58:264-70.

15 Kohama K, Yamashita H, Aoyama-Ishikawa M, Takahashi T, Billiar TR, Nishimura T, Kotani J, Nakao A. Hydrogen inhalation protects against acute lung injury induced by hemorrhagic shock and resuscitation. Surgery 2015;158:399-407.

16 Gong H, Wang W, Kwon TH, Jonassen T, Frøkiaer J, Nielsen S. Reduced renal expression of AQP2, p-AQP2 and AQP3 in haemorrhagic shock-induced acute renal failure. Nephrol Dial Transplant 2003;18:2551-9.

17 Zhao XG, Jiang SY, Zhang M, Zhou GJ, Zhao YY, Yi HX, Jiang LB, Wang JA. Ideal target arterial pressure after control of bleeding in a rabbit model of severe traumatic hemorrhagic shock: results from volume loading-based fluid resuscitation. J Surg Res 2015;196:358-67.

18 Bahrami S, Zimmermann K, Szelényi Z, Hamar J, Scheiflinger F, Redl H, Junger WG. Small-volume fluid resuscitation with hypertonic saline prevents inflammation but not mortality in a rat model of hemorrhagic shock. Shock 2006;25: 283-9.

19 Jin G, DeMoya MA, Duggan M, Knightly T, Mejaddam AY, Hwabejire J, Lu J, Smith WM, Kasotakis G, Velmahos GC, et al. Traumatic brain injury and hemorrhagic shock: evaluation of different resuscitation strategies in a large animal model of combined insults. Shock 2012;38:49-56

20 Gluud LL, Kjaer MS, Christensen E. Terlipressin for hepatorenal syndrome. Cochrane Database Syst Rev 2006;(4):CD005162.

21 Narahara Y, Kanazawa H, Taki Y, Kimura Y, Atsukawa M, Katakura T, Kidokoro H, Harimoto H, Fukuda T, Matsushita Y, et al. Effects of terlipressin on systemic, hepatic and renal hemodynamics in patients with cirrhosis. J Gastroenterol Hepatol 2009;24:1791-7.

22 Ida KK, Otsuki DA, Sasaki AT, Borges ES, Castro LU, Sanches TR, Shimizu MH, Andrade LC, Auler JO Jr, Dyson A, et al. Effects of terlipressin as early treatment for protection of brain in a model of haemorrhagic shock. Crit Care 2015;19:107.

23 Bayram B, Hocaoglu N, Atilla R, Kalkan S. Effects of terlipressin in a rat model of severe uncontrolled hemorrhage via liver injury. Am J Emerg Med 2012;30:1176-82.

24 Sauaia A, Moore EE, Johnson JL, Chin TL, Banerjee A, Sperry JL, Burlew CC. Temporal trends of postinjury multiple-organ failure: still resource intensive, morbid, and lethal. J Trauma Acute Care Surg 2014;76:582-92.

25 Sakr Y, Vincent JL, Reinhart K, Groeneveld J, Michalopoulos A, Sprung CL, Artigas A, Ranieri VM; Sepsis Occurence in Acutely III Patients Investigators. High tidal volume and positive fluid balance are associated with worse outcome in acute lung injury. Chest 2005;128:3098-108.

26 Van Biesen W, Yegenaga I, Vanholder R, Verbeke F, Hoste E, Colardyn F, Lameire N. Relationship between fluid status and its management on acute renal failure (ARF) in intensive care unit (ICU) patients with sepsis: a prospective analysis. J Nephrol 2005; 18:54-60.

27 Wiedemann HP, Wheeler AP, Bernard GR, Thompson BT, Hayden D, deBoisblanc B, Connors AF Jr, Hite RD, Harabin AL, National Heart, Lung, and Blood Institute Acute Respiratory Distress Syndrome (ARDS) Clinical Trials Network. Comparison of two fluid-management strategies in acute lung injury. N Engl I Med 2006;354:2564-75.

28 Peng Z, Pati S, Potter D, Brown R, Holcomb JB, Grill R, Wataha K, Park PW, Xue H, Kozar RA. Fresh frozen plasma lessens pulmonary endothelial inflammation and hyperpermeability after hemorrhagic shock and is associated with loss of syndecan 1. Shock 2013;40:195-202. 
29 Lee CC, Lee MT, Chang SS, Lee SH, Huang YC, Yo CH, Lee SH, Chen SC. A comparison of vasopressin, terlipressin, and lactated ringers for resuscitation of uncontrolled hemorrhagic shock in an animal model. PLOS ONE 2014:9:e95821.

30 Wohlauer MV, Sauaia A, Moore EE, Burlew CC, Banerjee A, Johnson J. Acute kidney injury and posttrauma multiple organ failure: the canary in the coal mine. J Trauma Acute Care Surg 2012;72:373-9.

31 Yim SY, Seo YS, Jung CH, Kim TH, Kim ES, Keum B, Kim JH, An H, Yim HJ, Yeon JE, et al. Risk factors for developing hyponatremia during terlipressin treatment: a retrospective analyses in variceal bleeding. I Clin Gastroenterol 2015;49:607-12.

32 Spinella PC, Perkins JG, Grathwohl KW, Repine T, Beekley AC, Sebesta J, Jenkins D, Azarow K, Holcomb JB, 31st CSH Research Working Group. Fresh whole blood transfusions in coalition military, foreign National, and enemy combatant patients during Operation Iraqi Freedom at a U.S. combat support hospital. World J Surg 2008;32:2-6.

33 Malpuech-Brugère C, Nowacki W, Daveau M, Gueux E, Linard C, Rock E, Lebreton J, Mazur A, Rayssiguier Y. Inflammatory response following acute magnesium deficiency in the rat. Biochim Biophys Acta 2000;1501:91-8.

34 Hoffert JD, Chou CL, Knepper MA. Aquaporin-2 in the '-omics' era. J Biol Chem 2009;284:14683-7.

35 Kwon TH, Laursen UH, MArples D, Maunsbach AB, Knepper MA, Frokiaer J, Nielsen $\mathrm{S}$. Altered expression of renal AQPs and $\mathrm{Na}(+)$ transporters in rats with lithium-induced NDI. Am J Physiol Renal Physiol 2000;279:552-64.

36 Kwon TH, Frokiaer J, Han JS, Knepper MA, Nielsen S. Decreased abundance of major $\mathrm{Na}+$ transporters in kidneys of rats with ischemia induced acute renal failure. Am J Physiol Renal Physiol 2000;278:F925-39. 